\title{
New Quasi-One-Dimensional Organic-Inorganic Hybrid Material: 1,3-Bis(4-piperidinium)propane Pentachlorobismuthate(III) Synthesis, Crystal Structure, and Spectroscopic Studies
}

\author{
Hela Ferjani and Habib Boughzala \\ Laboratoire de Cristallochimie et des Matériaux, Faculté des Sciences de Tunis, Université de Tunis El Manar, \\ El Manar I, 2092 Tunis, Tunisia
}

Correspondence should be addressed to Hela Ferjani; ferjani97@ymail.com

Received 5 December 2013; Accepted 12 February 2014; Published 2 June 2014

Academic Editor: Christian M. Julien

Copyright (C) $2014 \mathrm{H}$. Ferjani and H. Boughzala. This is an open access article distributed under the Creative Commons Attribution License, which permits unrestricted use, distribution, and reproduction in any medium, provided the original work is properly cited.

\begin{abstract}
The organic-inorganic hybrid compound $\left(\mathrm{C}_{13} \mathrm{H}_{28} \mathrm{~N}_{2}\right) \mathrm{BiCl}_{5}$ was synthesized by solvothermal method. The crystal structure was solved by single-crystal X-ray diffraction. The compound crystallizes in the orthorhombic system space group Cmc $2_{1}$ with $a=$ 15.826(4) $\AA, b=18.746(6) \AA, c=7.470(3) \AA$, and $Z=4$. The crystal structure was refined down to $R=0.019$. It consists of corrugated layers of $\left[\mathrm{BiCl}_{5}\right]^{2-}$ chains, separated by organic $\left[\mathrm{H}_{2} \mathrm{TMDP}\right]^{2+}$ cations (TMDP=1,3-Bis(4-piperidyl)propane $=\mathrm{C}_{13} \mathrm{H}_{26} \mathrm{~N}_{2}$ ). The crystal cohesion is achieved by hydrogen bonds $\mathrm{N}-\mathrm{H} \cdots \mathrm{Cl}$ joining the organic and inorganic layers. The influence of the organic cations' flexibility is discussed. Raman and infrared spectra of the title compound were recorded in the range of 50-400 and 400$4000 \mathrm{~cm}^{-1}$, respectively. Semiempirical parameter model three (PM3) method has been performed to derive the calculated IR spectrum. The crystal shape morphology was simulated using the Bravais-Friedel and Donnay-Harker model.
\end{abstract}

\section{Introduction}

Halobismuthates organic-inorganic hybrids are interesting systems because of the opportunity to combine the organic and the inorganic materials' proprieties. Nowadays, these compounds are the subject of intense investigations in many fields like optoelectronics and semiconducting [1-4]. The anionic sublattices of these materials are often built up by distorted $\left[\mathrm{BiX}_{6}\right]^{3-}$ octahedra $(\mathrm{X}=$ halogen). These octahedra can be isolated or linked by corners, edges, or faces leading to low dimensional inorganic framework. It is still a great challenge to control the structure dimensionalities of metal-halide anionic frameworks. In fact, the structural type depends on the experimental conditions, such as the solvent, ratio of reagents, and temperature. The organic cation size, charge, steric encumbrance, and the conformation can have a decisive influence. The organic moiety can be used as physical and electronic barrier, contributing to original electrical and optical behavior [5-8]. In these materials the crystal packing is directed by the interactions between the components constituting the solid such as hydrogen bonding, Van Der Waals, and electrostatic interactions.

In this work we present the results of the structural and spectroscopic studies on a new pentachlorobismuthatebased hybrid compound. Semiempirical parameter model three (PM3) computations are used in order to perform the vibrational analysis of the studied structure.

\section{Materials and Methods}

2.1. Synthesis. In a $23 \mathrm{~mL}$ teflon autoclave, a mixture of bismuth chloride $\mathrm{BiCl}_{3}$ and 1,3-bis(4-pyridyl) propane (TMDP) in molar ratio 1:2 was dissolved in $10 \mathrm{~mL}$ of absolute ethanol. The autoclave was heated to $140^{\circ} \mathrm{C}$ for three days. Colorless crystals were isolated from the mixture after cooling to room temperature. A suitable single crystal was selected for the structural determination. 
TABLE 1: Crystal data and structure refinement details for $\left(\mathrm{H}_{2} \mathrm{TMDP}\right) \mathrm{BiCl}_{5}$.

\begin{tabular}{|c|c|}
\hline \multicolumn{2}{|l|}{ Crystal data } \\
\hline Empirical formula & $\mathrm{C}_{13} \mathrm{H}_{28} \mathrm{~N}_{2} \cdot \mathrm{BiCl}_{5}$ \\
\hline Formula weight (g/mol) & 598.60 \\
\hline Crystal system, space group & Orthorhombic, $\mathrm{Cmc}_{1}$ \\
\hline$a(\AA)$ & $15.826(4)$ \\
\hline$b(\AA)$ & $18.746(6)$ \\
\hline$c(\AA)$ & $7.470(3)$ \\
\hline$V\left(\AA^{3}\right)$ & 2216.2(13) \\
\hline$Z$ & 4 \\
\hline$\mu\left(\mathrm{mm}^{-1}\right)$ & 8.56 \\
\hline$D_{x}\left(\mathrm{Mg} \mathrm{m}^{-3}\right)$ & 1.794 \\
\hline$F(000)$ & 1152 \\
\hline Crystal size (mm) & $0.56 \times 0.31 \times 0.24$ \\
\hline Crystal habit & Colorless Prism \\
\hline \multicolumn{2}{|l|}{ Data collection } \\
\hline Diffractometer & Enraf Nonius CAD4 \\
\hline Monochromater & Graphite \\
\hline Radiation type, $\lambda(\AA)$ & Mo K $\alpha, 0.71073$ \\
\hline$T(\mathrm{~K})$ & 298 \\
\hline Indexes range & $\begin{array}{c}-1 \leq h \leq 20 ;-23 \leq k \leq 3 ; \\
-1 \leq l \leq 9\end{array}$ \\
\hline Absorption correction: & psi-scan \\
\hline$T_{\min } / T_{\max }$ & $0.675 / 0.999$ \\
\hline Measured reflections & 1944 \\
\hline Independent reflections & 1541 \\
\hline Observed refl. with $I>2 \sigma(I)$ & 1476 \\
\hline$R_{\text {int }}$ & 0.014 \\
\hline \multicolumn{2}{|l|}{ Refinement } \\
\hline Refinement on & $F^{2}$ \\
\hline Data/restraints/parameters & $1476 / 1 / 104$ \\
\hline$R\left[F^{2}>2 \sigma\left(F^{2}\right)\right]$ & 0.019 \\
\hline$w R\left(F^{2}\right)$ & 0.046 \\
\hline $\mathrm{GoF}=\mathrm{S}$ & 1.10 \\
\hline$\Delta \rho_{\max } / \Delta \rho_{\min }\left(\mathrm{e} \cdot \AA^{-3}\right)$ & $0.73 /-1.02$ \\
\hline CCDC deposit number & 800676 \\
\hline
\end{tabular}

2.2. X-Ray Data Collection. The data was collected using an Enraf-Nonious CAD-4 X-Ray diffractometer [10] at $298 \mathrm{~K}$ equipped with graphite monochromator and $\mathrm{MoK} \alpha$ radiation $(\lambda=0.71073 \AA)$ using the $\omega / 2 \theta$ scan mode. An empirical psi-scan [11] absorption correction was applied. The structure was refined by Full-matrix least-squares based on $F^{2}$ using SHELXL-97 [12]. All nonhydrogen atoms were directly located from difference Fourier maps and refined with anisotropic displacement parameters. Hydrogen atoms were located at their idealized positions using appropriate HFIX instructions in SHELXL-97 [12] and included in subsequent least-squares refinement cycles in riding-motion approximation. Molecular graphics were prepared using Diamond 3
[13]. CCDC-800676 contains the supplementary crystallographic data for this paper. These data can be obtained free of charge at http://www.ccdc.cam.ac.uk/conts/retrieving.html or from the Cambridge Crystallographic Data Centre (CCDC), 12 Union Road, Cambridge CB2 1EZ, UK; fax: +44(0)1223-336033; email: deposit@ccdc.cam.ac.uk. Crystal data and parameters of the final refinement are reported in Table 1 .

2.3. Physicochemical Characterization Techniques. Room temperature infrared absorption spectrum was recorded in $400-4000 \mathrm{~cm}^{-1}$ frequency range on a Perkin Elmer Paragon 1000 Pc spectrometer by dispersing 2\% of the studied compound in $\mathrm{KBr}$ discs. Raman scattering was excited by $488 \mathrm{~nm}$ wavelength and recorded at room temperature using a JOKIN-YVON (T64000) spectrometer. Optical absorption spectrum of the $\left(\mathrm{C}_{13} \mathrm{H}_{28} \mathrm{~N}_{2}\right) \mathrm{BiCl}_{5}$ pellets was measured at room temperature using a UV-Visible absorption spectrometer Perkin Elmer Lambda 45. The $\mathrm{X}$-ray powder diffraction measurement was performed on a D8 ADVANCE BRUKER diffractometer using $\mathrm{Cu} \mathrm{K}_{\alpha 1 / \alpha 2}$ radiations and equipped with Lynxeye accelerator.

\section{Results and Discussion}

3.1. X-Ray Diffraction Characterization. The X-ray powder diffraction measurement was carried out to check the title compound purity using the raw X-ray powder diffraction and the structural investigation results. As shown in Figure 1, the similarity of the calculated pattern and the observed one confirms the high purity level of the synthesised phase.

3.2. Structure Description and Comparison. The asymmetric part of the unit cell consists of a half $\left(\mathrm{H}_{2} \text { TMDP }\right)^{2+}$ cation, one $\mathrm{Bi}(\mathrm{III})$ cation, and four $\mathrm{Cl}^{-}$anions as shown in Figure 2. The inorganic secondary building unit consists of a cis corner-sharing $\mathrm{BiCl}_{6}$ distorted octahedra running along the (001) crystallographic direction (Figure 3). The zigzag anionic chains have been observed in several other halobismuthate materials $[14,15]$. The shortest $\mathrm{Bi}-\mathrm{Bi}$ distance characterizing the chain period (Figure 4) has been found to be the significant structural parameter, determining the volume of the cavities occupied by $\left(\mathrm{H}_{2} \mathrm{TMDP}\right)^{2+}$ cations.

Therefore, these cations are stacked between the inorganic sheets, forming zigzag chains (Figure 3), and linked to them by weak intermolecular hydrogen bonds $\mathrm{N}-\mathrm{H} \cdots \mathrm{Cl}$ via terminal nitrogen atoms; N1-H0A $\cdots \mathrm{Cl} 3=3.35 \AA$ and N1H0B $\cdots$ Cl1 $=3.34 \AA$ (Figure 5(a)). These flexible bidentate cations adopt the anti-anti (TT) conformation, which is the most stable among others [16]. The shortest $\mathrm{N}-\mathrm{H} \cdots \mathrm{Cl}$ hydrogen bond geometries are presented in Table 3 . The resulting $1 \mathrm{D}$ chains of cations and those of anions are packed tightly in alternating mode to form a 3D network (Figure 3). The $\mathrm{Cl}-\mathrm{Bi}-\mathrm{Cl}$ angles vary from $84.77(5)^{\circ}$ to $95.49(1)^{\circ}$ for cis and $169.52(1)^{\circ}$ to $173.70(7)^{\circ}$ for trans arrangements (Table 2). The longest $\mathrm{Bi}-\mathrm{Cl}$ bond lengths fall in the range 2.533(3) $\AA$ 3.046(2) $\AA$ for the bivalent bridging chlorine. On the other 
TABLE 2: Selected bond distances $(\AA)$ and angles $\left({ }^{\circ}\right)$ for $\left(\mathrm{H}_{2} \mathrm{TMDP}\right) \mathrm{BiCl}_{5}$.

\begin{tabular}{|c|c|c|c|}
\hline \multicolumn{4}{|c|}{ Bond distances $(\AA)$} \\
\hline $\mathrm{Bi}-\mathrm{Cll}^{\mathrm{i}}$ & $2.6936(14)$ & $\mathrm{C} 1-\mathrm{C} 2$ & $1.498(8)$ \\
\hline $\mathrm{Bi}-\mathrm{Cl} 1$ & $2.6936(14)$ & $\mathrm{C} 2-\mathrm{C} 3$ & $1.522(7)$ \\
\hline $\mathrm{Bi}-\mathrm{Cl} 2$ & $2.533(3)$ & $\mathrm{C} 3-\mathrm{C} 4$ & $1.533(9)$ \\
\hline $\mathrm{Bi}-\mathrm{Cl} 3$ & $2.665(3)$ & $\mathrm{C} 4-\mathrm{C} 5$ & $1.520(8)$ \\
\hline $\mathrm{Bi}-\mathrm{Cl} 4$ & $2.769(3)$ & $\mathrm{C} 3-\mathrm{C} 6$ & $1.519(9)$ \\
\hline $\mathrm{Bi}-\mathrm{Cl} 4^{\mathrm{ii}}$ & $3.046(2)$ & $\mathrm{C} 6-\mathrm{C} 7$ & $1.580(14)$ \\
\hline $\mathrm{N}-\mathrm{C} 1$ & $1.497(7)$ & $\mathrm{C} 3-\mathrm{C} 4$ & $1.533(9)$ \\
\hline $\mathrm{N}-\mathrm{C} 5$ & $1.498(7)$ & & \\
\hline \multicolumn{4}{|l|}{ Angles $\left({ }^{\circ}\right)$} \\
\hline $\mathrm{Cl} 2-\mathrm{Bi}-\mathrm{Cl} 3$ & $95.49(10)$ & $\mathrm{C} 6-\mathrm{C} 3-\mathrm{C} 2$ & $110.7(7)$ \\
\hline $\mathrm{Cl} 2-\mathrm{Bi}-\mathrm{Cl} 1$ & $84.77(5)$ & $\mathrm{C} 6-\mathrm{C} 3-\mathrm{C} 4$ & $113.6(8)$ \\
\hline $\mathrm{Cl} 3-\mathrm{Bi}-\mathrm{Cl} 1$ & $90.13(7)$ & $\mathrm{C} 2-\mathrm{C} 3-\mathrm{C} 4$ & 109.1(6) \\
\hline $\mathrm{Cll}^{\mathrm{i}}-\mathrm{Bi}-\mathrm{Cl} 1$ & $169.52(10)$ & $\mathrm{C} 5-\mathrm{C} 4-\mathrm{C} 3$ & $113.4(6)$ \\
\hline $\mathrm{Cl} 2-\mathrm{Bi}-\mathrm{Cl} 4$ & $90.81(9)$ & $\mathrm{N}-\mathrm{C} 5-\mathrm{C} 4$ & $109.3(6)$ \\
\hline $\mathrm{Cl} 3-\mathrm{Bi}-\mathrm{Cl} 4$ & $173.70(7)$ & $\mathrm{N}-\mathrm{C} 1-\mathrm{C} 2$ & $109.4(5)$ \\
\hline $\mathrm{Cl} 1-\mathrm{Bi}-\mathrm{Cl} 4$ & $90.45(6)$ & $\mathrm{C} 1-\mathrm{C} 2-\mathrm{C} 3$ & $113.1(6)$ \\
\hline $\mathrm{Cl} 2-\mathrm{Bi}-\mathrm{Cl} 4^{\mathrm{ii}}$ & $172.17(8)$ & $\mathrm{C} 3-\mathrm{C} 6-\mathrm{C} 7$ & $111.4(9)$ \\
\hline $\mathrm{Cl} 3-\mathrm{Bi}-\mathrm{Cl} 4^{\mathrm{ii}}$ & $92.34(8)$ & $\mathrm{C} 6^{\mathrm{i}}-\mathrm{C} 7-\mathrm{C} 6$ & $105.8(13)$ \\
\hline $\mathrm{Cl} 1-\mathrm{Bi}-\mathrm{Cl} 4^{\mathrm{ii}}$ & $95.23(5)$ & & \\
\hline $\mathrm{Cl} 4-\mathrm{Bi}-\mathrm{Cl} 4^{\mathrm{ii}}$ & $81.36(3)$ & & \\
\hline $\mathrm{Bi}-\mathrm{Cl} 4-\mathrm{Bi}^{\mathrm{iii}}$ & $165.87(10)$ & & \\
\hline $\mathrm{C} 1-\mathrm{N}-\mathrm{C} 5$ & $112.8(5)$ & & \\
\hline
\end{tabular}

TABLE 3: Hydrogen bonds and angles for $\left(\mathrm{H}_{2} \mathrm{TMDP}\right) \mathrm{BiCl}_{5}\left(\AA{ }^{\circ}\right)$.

\begin{tabular}{lcccc}
\hline D-H $\cdots$ A & D-H & H $\cdots A$ & D $\cdots A$ & D-H $\cdots A$ \\
\hline N1-H0A $\cdots \mathrm{Cl}^{\text {iv }}$ & 0.9 & 2.48 & 3.357 & 165 \\
N1-H0B $\cdots \mathrm{Cll}^{\mathrm{v}}$ & 0.9 & 2.45 & 3.340 & 169 \\
\hline
\end{tabular}

Symmetry codes: ${ }^{\mathrm{iv}} x, y, z+1 ;{ }^{\mathrm{v}}-x, y, z+1$.

hand, the shortest ones are for the monovalent anions pointing to the organic cationic space (Figure 4). It is worth noting that the $\mathrm{H}_{2}$ TMDP is a flexible cation and endowed with many conformations. This flexibility presents an important effect in the formation of the inorganic chains leading to multiple structures [17].

Goforth et al. [9] synthesized a new compound containing a polymeric mixed haloanion $\left(\mathrm{H}_{2} \mathrm{TMDP}\right) \mathrm{BiBr}_{4.01} \mathrm{I}_{0.99}$ and presenting similarities with the title compound. Before making any structural comparison, it is necessary to standardize the networks of the two structures (see Table 4). The presence of two halogen $(\mathrm{Br}, \mathrm{I})$ larger size than the chlorine increases the cell volume of about $68 \AA^{3}$. In spite of the inorganic part arrangement similarities the $\left(\mathrm{H}_{2} \mathrm{TMDP}\right)$ $\mathrm{BiBr}_{4.01} \mathrm{I}_{0.99}$ structure exhibits a different organic part organization. In fact, in the title structure the cations penetrate into the anionic chains cavities while in the homologous compound they are located just between these chains (Figure 6).

The organic cations conformation is probably the main differentiating feature between the two structures. Indeed, in our case $\left(\mathrm{H}_{2}\right.$ TMDP) presents a TT conformation (the $\mathrm{N}-\mathrm{N}$

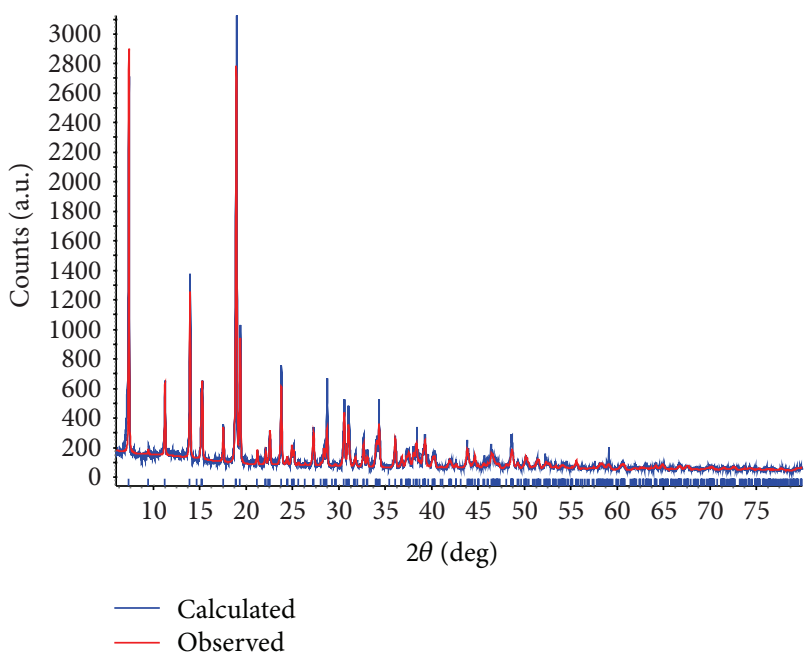

Figure 1: Observed (red line) and calculated (blue line) powder Xray diffraction patterns of $\left(\mathrm{H}_{2} \mathrm{TMDP}\right) \mathrm{BiCl}_{5}$.

distance in the a direction is equal to $10.643 \AA$ ), whereas in the homologous compound it adopts a TG conformation with a shorter N-N distance $(8.645 \AA$ ) (see Figures 5(a) and 5(b)). This induces a closeness between the nearest inorganic layers lodging the organic cations and reducing the parameter $a$ of about 6\% $(a=15.826(4) A=14.899(9) \AA)$.

In addition, these cations are propagated in zigzag chains perpendicular to $b$ axis in the hollow cavities of the anionic 
TABLE 4: The crystallographic parameters of $\left(\mathrm{H}_{2} \mathrm{TMDP}\right) \mathrm{BiBr}_{4.01} \mathrm{I}_{0.99}$ and $\left(\mathrm{H}_{2} \mathrm{TMDP}\right) \mathrm{BiCl}_{5}$.

\begin{tabular}{lccc}
\hline Compound & $\left(\mathrm{H}_{2} \mathrm{TMDP} \mathrm{BiBr}_{4.01} \mathrm{I}_{0.99}\right.$ & $\left(\mathrm{H}_{2} \mathrm{TMDP} \mathrm{BiBr}_{4.01} \mathrm{I}_{0.99}[9]\right.$ & $\left(\mathrm{H}_{2} \mathrm{TMDP} \mathrm{BiCl}_{5}{ }^{*}\right.$ \\
\hline Space group & $\mathrm{P} 2_{1} 2_{1} 2_{1}$ & $\mathrm{P} 2_{1} 2_{1} 2_{1}$ & $\mathrm{Cmc} 2_{1}$ \\
Crystal system & Orthorhombic & Orthorhombic & Orthorhombic \\
$a(\AA)$ & $8.5189(5)$ & $A=14.8988(9)$ & $a=15.826(4)$ \\
$b(\AA)$ & $14.8988(9)$ & $B=17.9984(11)$ & $b=18.746(6)$ \\
$c(\AA)$ & $17.9984(11)$ & $C=8.5189(5)$ & $c=7.470(3)$ \\
$V\left(\AA^{3}\right)$ & $2284.4(2)$ & $2284.4(2)$ & $2216.2(2)$ \\
$Z$ & 4 & 4 & 4 \\
Cation conformation & $\mathrm{TG}$ & $\mathrm{TG}$ & $\mathrm{TT}$ \\
\hline
\end{tabular}

${ }^{*}$ This work.

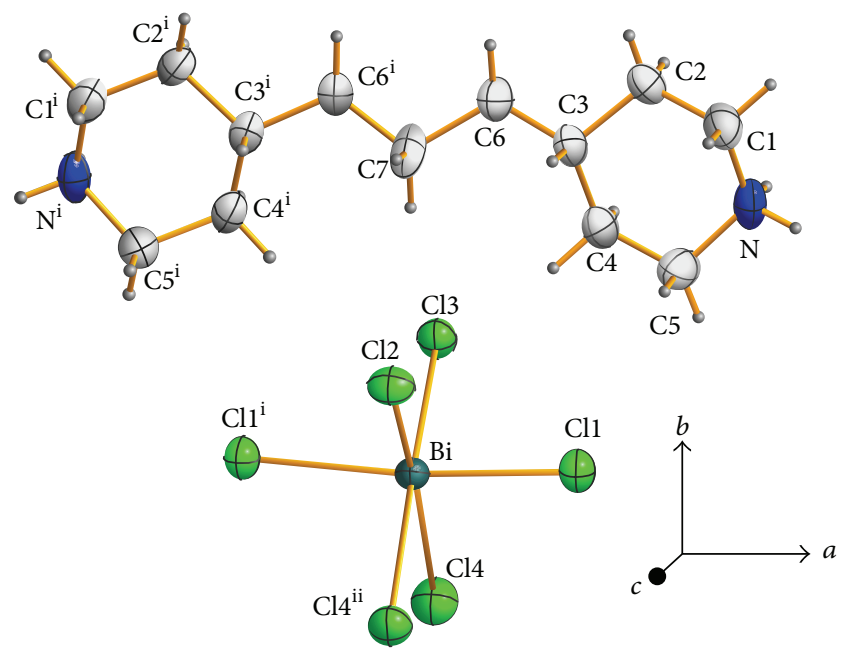

Figure 2: The asymmetric unit part of the ( $\left.\mathrm{H}_{2} \mathrm{TMDP}\right) \mathrm{BiCl}_{5}$ compound showing the atom numbering scheme. Displacement ellipsoids are drawn at the $50 \%$ probability level. The superscripts (i) and (ii) indicate the symmetry positions $(-x, y, z)$ and $(-x,-y,-1 / 2+z)$.

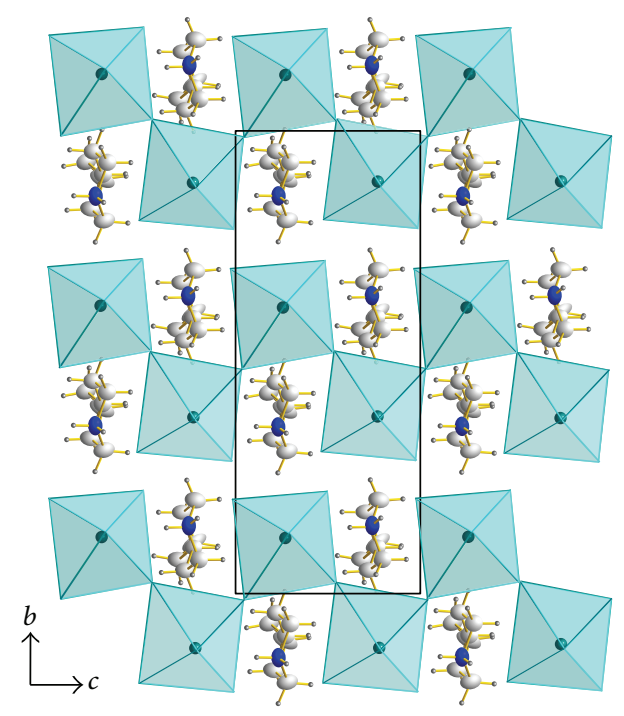

FIGURE 3: View of the structure of $\left(\mathrm{H}_{2} \mathrm{TMDP}\right) \mathrm{BiCl}_{5}$ along the $c$ axis showing the zigzag chains of the $\mathrm{BiCl}_{6}$ octahedra and the cations.

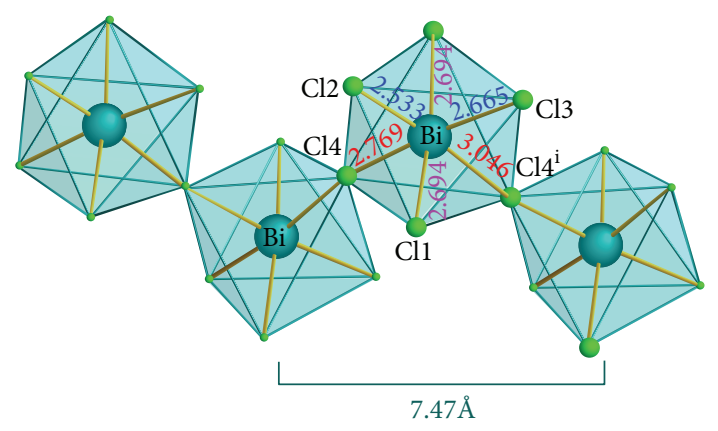

Figure 4: Anionic chain and the $\mathrm{Bi}-\mathrm{Bi}$ distance in ( $\mathrm{H}_{2}$ TMDP) $\mathrm{BiCl}_{5}$ crystal.

chain (in our case) and leaves empty channels (Figure 6(a)) between the organic-inorganic chains, whereas in the homologous compound cations occupy the whole of the empty space between the anionic chains, leading to an elongation of parameter $b$ from $B=17.9984(11) b=18.746(6) \AA(4 \%)$.

The observed distortion in the ( $\left.\mathrm{H}_{2} \mathrm{TMDP}\right) \mathrm{BiBr}_{4.01} \mathrm{I}_{0.99}$ octahedra compared to those of the title compound is probably due to the replacement of chloride anions by mixed halogens $(\mathrm{Br} / \mathrm{I})$. Indeed, the distance $\mathrm{Bi}-\mathrm{Br}_{\text {bridging }}=3.1258(8) \AA$ [9] is slightly longer than $\mathrm{Bi}-\mathrm{Cl}_{\text {bridging }}=3.046(2) \AA$. In addition, the ammonium group located between the cavities is linked by two hydrogen bonds to the main inorganic framework vertices $(\mathrm{N}-\mathrm{H} 0 \mathrm{~A} \cdots \mathrm{Cl} 3,3.357(6) \AA, \mathrm{N}-$ H0B ... Cl1, 3.340(7) $\AA$ ). The hydrogen bonds network gets closer to the octahedra chains and decreases the $c$ parameter

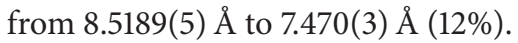

3.3. Crystal Morphology. Crystal morphology is a key element in many industrial processes and has an enormous impact in the materials processing stages. Thus, rationalization of the relationships between crystal morphology and the arrangement of atoms in the bulk crystal lattice is of great interest in many areas of science. In this way, we wanted to provide a comprehensive understanding of the crystal structure-morphology relationships in this material.

The crystal morphology of the title compound was predicted using the Bravais-Fridel, Donnay-Harker model (BFDH) [18-20] (Figure 7(a)). It uses the crystal lattice and symmetry to generate a list of possible growth faces and 


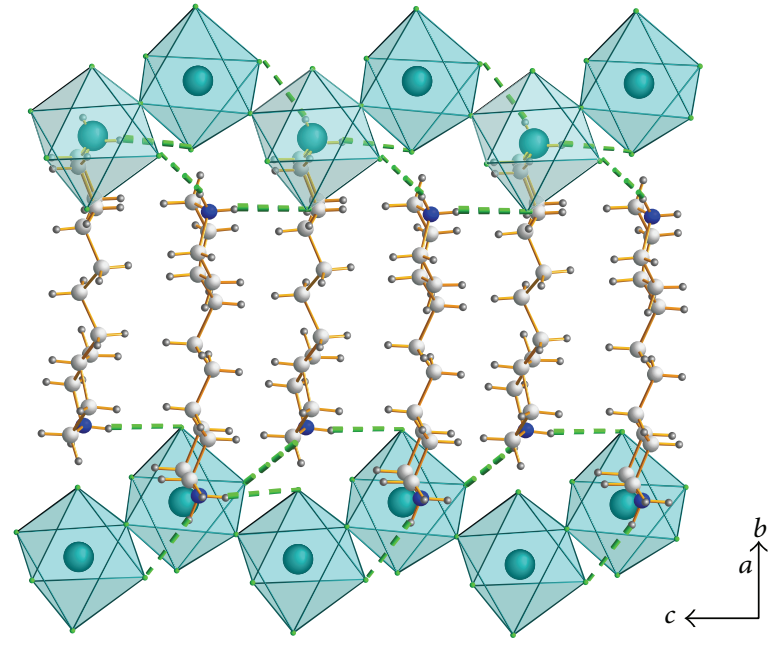

(a)

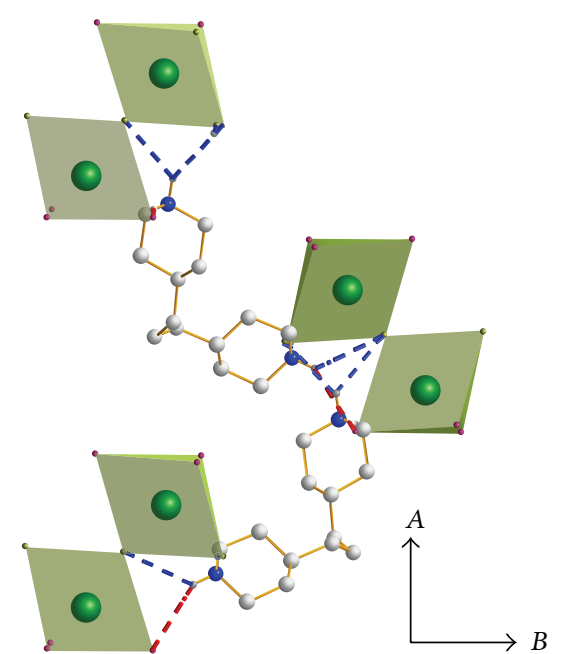

(b)

Figure 5: A view showing the $\mathrm{N}-\mathrm{H} \cdots \mathrm{Cl}$ (green) interactions in the crystal of $\left(\mathrm{H}_{2} \mathrm{TMDP} \mathrm{BiCl}_{5}(\mathrm{a}) \mathrm{N}-\mathrm{H} \cdots \mathrm{Br}(\mathrm{blue})\right.$ and $\mathrm{N}-\mathrm{H} \cdots \mathrm{I}($ red $)$ in $\left(\mathrm{H}_{2} \mathrm{TMDP}\right) \mathrm{BiBr}_{4.01} \mathrm{I}_{0.99}$ (b) (Hydrogen bonds shown as dashed lines).

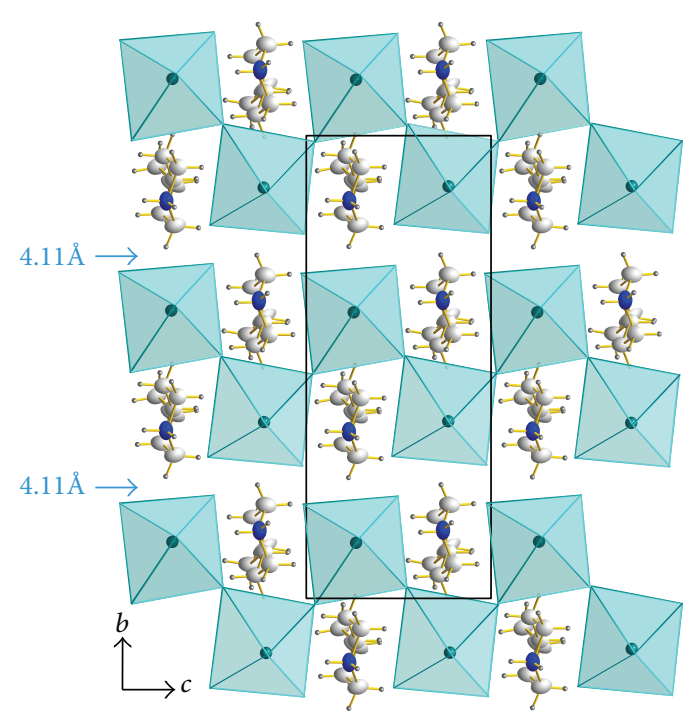

(a)

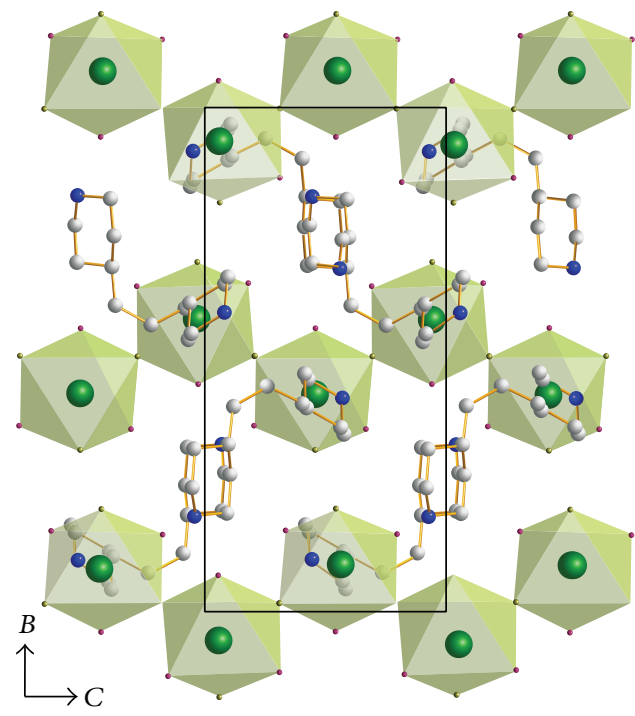

(b)

Figure 6: (001) views of the crystal packing in $\left(\mathrm{H}_{2} \mathrm{TMDP}\right) \mathrm{BiCl}_{5}$ (a) and $\left(\mathrm{H}_{2} \mathrm{TMDP}^{\mathrm{T}} \mathrm{BiBr}_{5-x} \mathrm{I}_{x}\right.$ (b) [9].

their relative growth rates. It allows understanding the crystal growth process. The prediction possessed a needle habit with the most developed $(\{110\},\{110\},\{1-10\},\{-1-10\})$ faces. New additional small faces $(\{020\},\{0-20\})$ that do not appear in the observed habit (Figure 7(b)) are also predicted. These calculations allow identifying the physical axes and the crystallographic ones.

3.4. Vibrational Study. To gain information on the crystal structure, we have carried out a vibrational study using infrared absorption and Raman scattering. The infrared and Raman spectra recorded at room temperature are shown in Figures 8(a) and 9, respectively. We have calculated the vibrational spectrum (Figure 8(b)) by using semiempirical PM3 geometry optimization by "CAChe" program [21]. The frequencies of the observed and calculated Raman and infrared peaks are reported in Table 5.

3.4.1. The Vibration of Piperidinium Cation $\left(\mathrm{H}_{2} \mathrm{TMDP}\right)^{2+}$. The infrared absorption spectrum of the title compound $\left(\mathrm{H}_{2} \mathrm{TMDP}\right) \mathrm{BiCl}_{5}$ shows corresponding vibration bands of 1,3-bis(4-piperidinium)propane cation. The assignments reported in Table 5 are in agreement with the calculated IR spectrum. These modes are well predicted by the calculation. The shift between the observed wave numbers and the calculated ones is probably due to the approximations used 


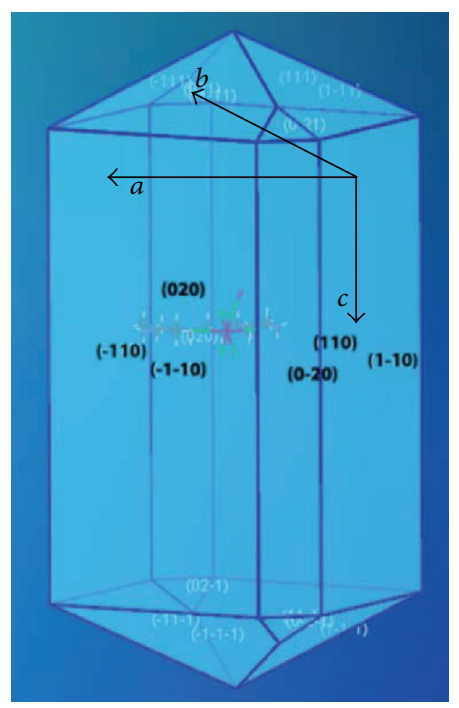

(a)

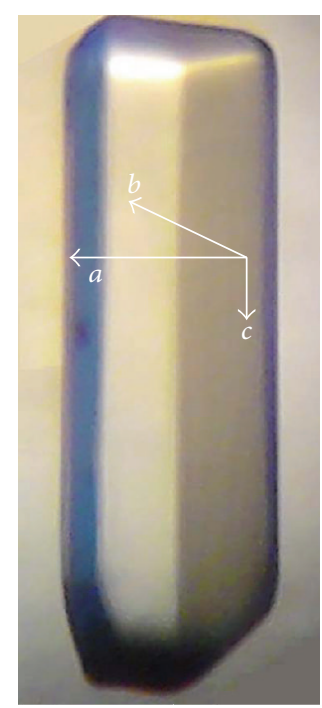

(b)

FIGURE 7: Growth shape from BFDH rules (a), images of the growth morphologies taken with the optical microscope $(b)$ of $\left(\mathrm{H}_{2} \mathrm{TMDP}\right) \mathrm{BiCl5}$.

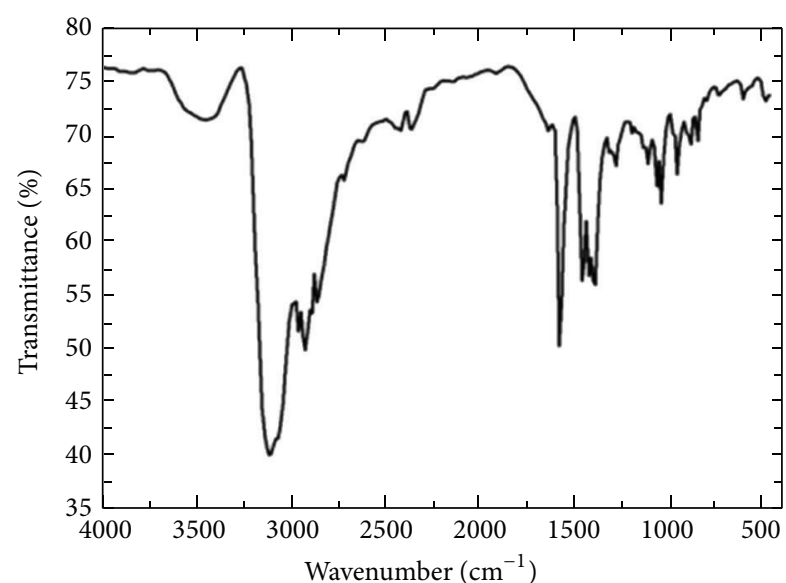

(a)

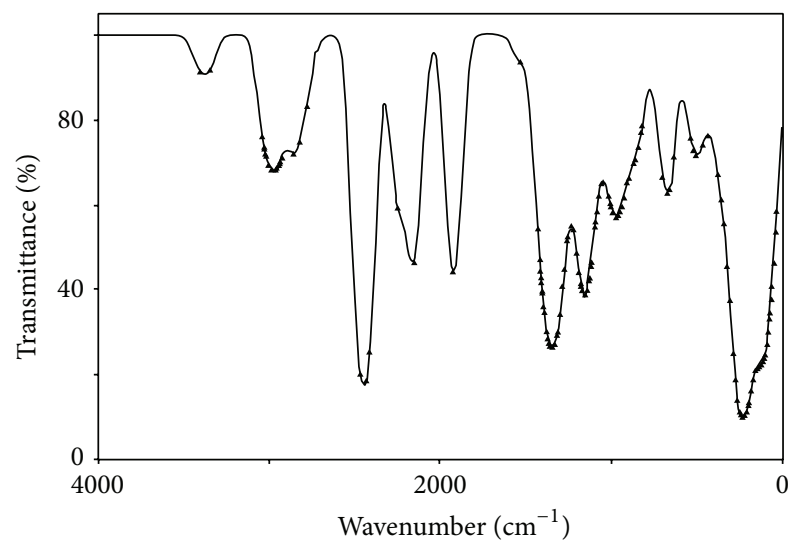

(b)

FIGURE 8: Room temperature IR spectra of $\left(\mathrm{H}_{2} \mathrm{TMDP}\right) \mathrm{BiCl}_{5}$ (a) and PM3 computed IR spectra (b).

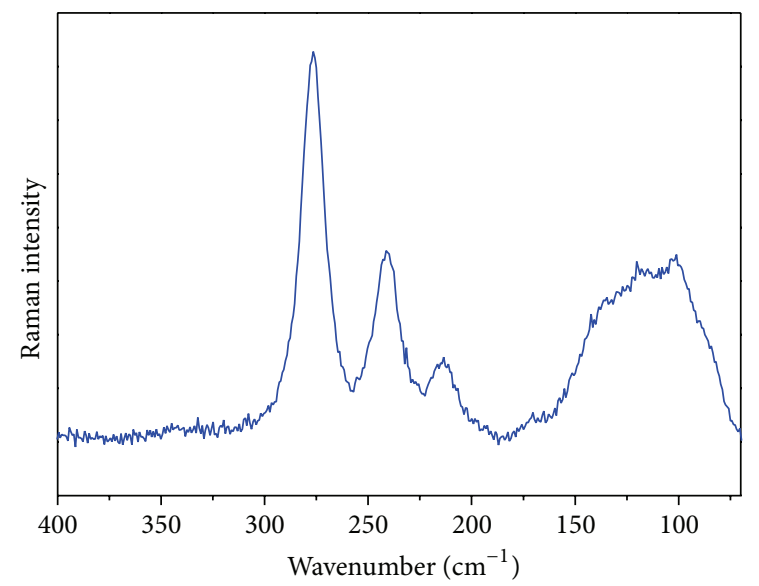

Figure 9: Raman spectra of $\left(\mathrm{H}_{2} \mathrm{TMDP}\right) \mathrm{BiCl}_{5}$ recorded at low frequency range.

in the computations. However, the groups are assumed to be free whereas actually they are engaged by hydrogen bonds.

Heterocyclic compounds containing an $\mathrm{N}-\mathrm{H}$ group exhibit $\mathrm{N}-\mathrm{H}$ stretching absorption in the region from 3500 to $3200 \mathrm{~cm}^{-1}$. The stretching vibrations of the $\mathrm{N}-\mathrm{H}$ group are observed at 3460 and $3110 \mathrm{~cm}^{-1}$. The infrared bands observed at $2980-2850 \mathrm{~cm}^{-1}$ region are assigned $\mathrm{CH}$ stretching for piperidine $[16,22]$. In the 1,3 -bis(4-piperidyl)propane, the stretching of CH modes experimentally are observed at 2920$2856 \mathrm{~cm}^{-1}$ region. The stretching modes of $\mathrm{CN}$ are observed around $1180-1100 \mathrm{~cm}^{-1}$ for piperidine $[16,22]$. Piperidine ring CC stretching modes are obtained in the range 1350$1073 \mathrm{~cm}^{-1}[16,22]$. The $\mathrm{C}-\mathrm{H}$ stretching absorption of methylene group is centered on $2925 \mathrm{~cm}^{-1}$. The infrared band 


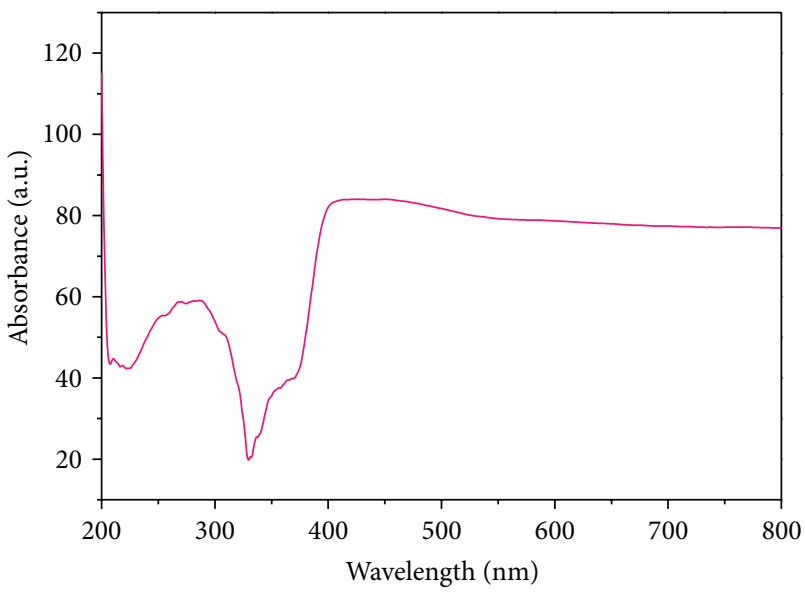

FIGURE 10: Diffuse reflectance UV-Visible absorption spectra for $\left(\mathrm{H}_{2} \mathrm{TMDP}\right) \mathrm{BiCl}_{5}$.

TABLE 5: Observed and calculated vibration frequencies $\left(\mathrm{cm}^{-1}\right)$ of $\left(\mathrm{H}_{2} \mathrm{TMDP}\right) \mathrm{BiCl}_{5}$ and proposed assignments.

\begin{tabular}{lccl}
\hline $\begin{array}{l}\text { Calculated } \\
\text { infrared }\end{array}$ & $\begin{array}{c}\text { Observed } \\
\text { FT-Raman }\end{array}$ & FT-IR & Assignments \\
\hline- & 100 & - & Bending \\
- & 120 & - & modes \\
- & 214 & - & Bi-Cl (Bridge) stretch \\
- & 240 & - & Bi-Cl \\
- & 278 & - & $($ external $)$ stretch \\
- & - & 954 & $\delta(\mathrm{C}-\mathrm{C})$ \\
992 & - & 1073 & $v_{s}(\mathrm{C}-\mathrm{C})$ \\
1178 & - & 1272 & $v(\mathrm{C}-\mathrm{N})$ \\
1368 & - & 1380 & $v_{\text {as }}(\mathrm{C}-\mathrm{C})$ \\
- & - & 1460 & $\delta(\mathrm{CH})$ \\
- & - & 1580 & $\delta\left(\mathrm{NH}_{2}\right)$ \\
2489 & - & 2856 & $v_{s}(\mathrm{C}-\mathrm{H})$ \\
2899 & - & 2920 & $v_{\text {as }}(\mathrm{C}-\mathrm{H})$ \\
3029 & - & 3110 & $v_{s}\left(\mathrm{NH}_{2}\right)$ \\
3428 & - & 3460 & $v_{\text {as }}\left(\mathrm{NH}_{2}\right)$ \\
\hline
\end{tabular}

observed at $2856 \mathrm{~cm}^{-1}$ is assigned to symmetric $\mathrm{CH}_{2}$ for methylene group. The asymmetric stretching mode of methylene group is observed at $2920 \mathrm{~cm}^{-1}$.

3.4.2. The Vibration of $\mathrm{BiCl}_{6}{ }^{3-}$. Based on some studies carried out for previous works and reported on similar compounds containing $\left(\mathrm{BiCl}_{5}\right)^{2-}$ anions $[23,24]$, we propose an attempt of assignment of the observed bands. The low Raman frequencies of $\left(\mathrm{H}_{2} \mathrm{TMDP}\right) \mathrm{BiCl}_{5}$ crystal can be assigned to vibrations of $\mathrm{BiCl}_{6}{ }^{3-}$ octahedral corner sharing. The $\mathrm{Bi}-\mathrm{Cl}$ stretching modes are observed in the low frequency range between 400 and $100 \mathrm{~cm}^{-1}$. The $278 \mathrm{~cm}^{-1}$ and $240 \mathrm{~cm}^{-1}$ bands are, respectively, assigned to the $\mathrm{Bi}-\mathrm{Cl}$ external antsymmetric and symmetric stretching. Raman lines at 214, 120, and $100 \mathrm{~cm}^{-1}$ most likely correspond to the $\mathrm{Bi}-\mathrm{Cl}$ bridging stretch and the $\mathrm{Cl}-\mathrm{Bi}-\mathrm{Cl}$ deformation.

3.5. UV-Visible Spectroscopy. In the UV-Vis absorption the chlorobismuthate(III) anions are characterized by metal centered (MC) sp and Ligand to metal centered transitions (LMCT) at lower wavelengths $[25,26]$. In fact, The LMCT may occur only at rather high energies and all long wavelength transitions were assigned to metal-centered transitions $[27,28]$.

The optical properties of 1,3-bis(4-piperidinium)propane pentachlorobismuthate(III) pellets were assessed by its UVVis absorption spectrum shown in Figure 10.

The $\left(\mathrm{H}_{2} \mathrm{TMDP}\right) \mathrm{BiCl}_{5}$ exhibits two distinct absorptions bands cantered at $287 \mathrm{~nm}$ and $410 \mathrm{~nm}$. The highest absorption peak at $410 \mathrm{~nm}$ is assigned to the Metal Centered (MC) transition from the $6 \mathrm{~s}$ to $6 \mathrm{~s} 6 \mathrm{p}$ of Bismuth atom. The band at $287 \mathrm{~nm}$ can be attributed to Ligand, to metal charge transfer (LMCT) transition from the $5 \mathrm{p}$ orbital of $\mathrm{Cl}$ to $6 \mathrm{p}$ orbital of $\mathrm{Bi}(\mathrm{III})$ as described in previous outputs [25-28].

\section{Conclusions}

The pseudo-one-dimensional (1D) organic-inorganic hybrid compound $\left(\mathrm{C}_{13} \mathrm{H}_{28} \mathrm{~N}_{2}\right) \mathrm{BiCl}_{5}$ consists of polymeric $\left[\mathrm{BiCl}_{5}\right]^{2-}$ entities with corner sharing $\mathrm{BiCl}_{6}$ octahedral geometry. Piperidinium cations are located in the empty space around $\mathrm{BiCl}_{6}$ chains and linked to the octahedra by hydrogen bonds. The vibrational properties of this structure were studied by Raman scattering and infrared spectroscopy. The assignment of the vibrational bands was performed by comparison with the vibration modes frequencies of homologous compounds and compared with the calculated spectrum. The optical properties were investigated by UV-Visible measurement. The crystal morphology was carried out using the Bravais-Friedel and Donnay-Harker model.

\section{Conflict of Interests}

The authors declare that there is no conflict of interest regarding the publication of this paper.

\section{References}

[1] W. Masmoudi, S. Kamoun, and H. F. Ayedi, "Synthesis and structure of bis(3-dimethylammonium-1-propyne) pentachlorobismuthate(III) $\left(\mathrm{C}_{5} \mathrm{H}_{10} \mathrm{~N}\right)_{2} \mathrm{BiCl}_{5}$," Journal of Chemical Crystallography, vol. 41, no. 5, pp. 693-696, 2011.

[2] A. Samet, H. Boughzala, H. Khemakhem, and Y. Abid, "Synthesis, characterization and non-linear optical properties of Tetrakis(dimethylammonium) Bromide Hexabromobismuthate: $\left[\left(\mathrm{CH}_{3}\right) 2 \mathrm{NH}_{2}\right]_{4}^{+} \cdot \mathrm{Br}^{-} \cdot\left[\mathrm{BiBr}_{6}\right]^{3-}$, , Journal of Molecular Structure, vol. 984, no. 1-3, pp. 23-29, 2010.

[3] A. Rhandour, A. Ouasri, P. Roussel, and A. Mazzah, "Crystal structure and vibrational studies of butylenediammonium pentachlorobismuthate (III) hydrate $\left[\mathrm{NH}_{3}\left(\mathrm{CH}_{2}\right)_{4} \mathrm{NH}_{3}\right] \mathrm{BiCl}_{5}$ $\cdot \mathrm{H}_{2} \mathrm{O}$,' Journal of Molecular Structure, vol. 990, no. 1-3, pp. 95101, 2011. 
[4] C. Hrizi, A. Trigui, Y. Abid, N. Chniba-Boudjada, P. Bordet, and S. Chaabouni, " $\alpha$ - to $\beta-\left[\mathrm{C}_{6} \mathrm{H}_{4}\left(\mathrm{NH}_{3}\right)_{2}\right]_{2} \mathrm{Bi}_{2} \mathrm{I}_{10}$ reversible solid-state transition, thermochromic and optical studies in the p-phenylenediamine-based iodobismuthate(III) material," Journal of Solid State Chemistry, vol. 184, no. 12, pp. 3336-3344, 2011.

[5] D. B. Mitzi, K. Chondroudis, and C. R. Kagan, "Design, structure, and optical properties of organic-inorganic perovskites containing an oligothiophene chromophore," Inorganic Chemistry, vol. 38, no. 26, pp. 6246-6256, 1999.

[6] C. Hrizi, A. Samet, Y. Abid, S. Chaabouni, M. Fliyou, and A. Koumina, "Crystal structure, vibrational and optical properties of a new self-organized material containing iodide anions of bismuth(III), $\left[\mathrm{C}_{6} \mathrm{H}_{4}\left(\mathrm{NH}_{3}\right)_{2}\right]_{2} \mathrm{Bi}_{2} \mathrm{I}_{10} \cdot 4 \mathrm{H}_{2} \mathrm{O}$," Journal of Molecular Structure, vol. 992, no. 1-3, pp. 96-101, 2011.

[7] A. Samet, A. B. Ahmed, A. Mlayah, H. Boughzala, E. K. Hlil, and Y. Abid, "Optical properties and ab initio study on the hybrid organic-inorganic material $\left[\left(\mathrm{CH}_{3}\right)_{2} \mathrm{NH}_{2}\right]_{3}\left[\mathrm{BiI}_{6}\right]$," Journal of Molecular Structure, vol. 977, no. 1-3, pp. 72-77, 2010.

[8] Y.-J. Wang and L. Xu, "Synthesis and optical properties of two novel chlorobismuthate(III) complexes: [8-Hydroxyquinolinium $]_{4} \mathrm{~K}_{2}\left[\mathrm{BiCl}_{6}\right]_{2} \cdot 6 \mathrm{H}_{2} \mathrm{O}$ (1) and [8-hydroxyquinolinium $]_{6}\left[\mathrm{Bi}_{2} \mathrm{Cl}_{10}\right]\left[\mathrm{BiCl}_{5}\left(\mathrm{H}_{2} \mathrm{O}\right)\right] \cdot 6 \mathrm{H}_{2} \mathrm{O}(2)$," Journal of Molecular Structure, vol. 875, no. 1-3, pp. 570-576, 2008.

[9] A. M. Goforth, M. D. Smith, L. Peterson Jr., and H.-C. Zur Loye, "Preparation and characterization of novel inorganicorganic hybrid materials containing rare, mixed-halide anions of bismuth(III)," Inorganic Chemistry, vol. 43, no. 22, pp. 70427049, 2004.

[10] A. J. M. Duisenberg, "Indexing in single-crystal diffractometry with an obstinate list of reflections," Journal of Applied Crystallography, vol. 25, no. 2, pp. 92-96, 1992.

[11] A. C. T. North, D. C. Phillips, and F. S. Mathews, "A semiempirical method of absorption correction," Acta Crystallographica A, vol. 24, pp. 351-359, 1968.

[12] G. M. Sheldrick, "A short history of SHELX," Acta Crystallographica Section A: Foundations of Crystallography, vol. 64, no. 1, pp. 112-122, 2007.

[13] K. Brandenburg, Diamond, Crystal Impact GbR, Bonn, Germany, 2008.

[14] H. Ferjani, H. Boughzala, and A. Driss, "Poly[bis(1-carbamoylguanidinium) [tri- $\mu$-chlorido-dichloridobismuthate(III)]]," Acta Crystallographica Section E: Structure Reports Online, vol. 68, no. 5, article m615, 2012.

[15] M. Owczarek, P. Szklarz, R. Jakubas, and A. Miniewicz, "MX 5: a new family of morpholinium nonlinear optical materials among halogenoantimonate(iii) and halogenobismuthate(iii) compounds. Structural characterization, dielectric and piezoelectric properties," Dalton Transactions, vol. 41, no. 24, pp. 7285-7294, 2012.

[16] Y. Erdoğdu, M. T. Güllüoğlu, and S. Yurdakul, "Molecular structure and vibrational spectra of 1,3-bis(4-piperidyl)propane by quantum chemical calculations," Journal of Molecular Structure, vol. 889, pp. 361-370, 2008.

[17] A. M. Goforth, L. Peterson Jr., M. D. Smith, and H.-C. Zur Loye, "Syntheses and crystal structures of several novel alkylammonium iodobismuthate materials containing the 1,3-bis-(4piperidinium)propane cation," Journal of Solid State Chemistry, vol. 178, no. 11, pp. 3529-3540, 2005.

[18] A. Bravais, Etudes Cristallographiques, Gauthier-Villars, Paris, France, 1913.
[19] G. Fridel, "Crystal habits of minerals," Bulletin de la Société Chimique de France, pp. 326-455, 1907.

[20] J. D. H. Donnay and D. Harker, Springer Handbook of Crystal Growth, American Mineralogist, 1937.

[21] Cache: worksystem Pro Version 7. 5. 0. 85, Fujitsu Limited. 2000-2006 Oxford Molecular.

[22] M. T. Güllüoǧlu, Y. Erdoğdu, and Ş. Yurdakul, "Molecular structure and vibrational spectra of piperidine and 4methylpiperidine by density functional theory and ab initio Hartree-Fock calculations," Journal of Molecular Structure, vol. 834-836, pp. 540-547, 2007.

[23] J. Tarasiewicz, R. Jakubas, and J. Baran, "Raman studies of the anionic sublattice vibrations in $\left(\mathrm{C}_{5} \mathrm{H}_{5} \mathrm{NH}\right)_{6} \mathrm{Bi}_{4} \mathrm{Cl}_{18}$," Journal of Molecular Structure, vol. 614, no. 1-3, pp. 333-338, 2002.

[24] A. Piecha, R. Jakubas, A. Pietraszko, and J. Baran, "Structural characterization and spectroscopic properties of imidazolium chlorobismuthate(III): $\left[\mathrm{C}_{3} \mathrm{H}_{5} \mathrm{~N}_{2}\right]_{6}\left[\mathrm{Bi}_{4} \mathrm{Cl}_{18}\right]$," Journal of Molecular Structure, vol. 844-845, pp. 132-139, 2007.

[25] A. Vogler and H. Nikol, "The Structures of $s^{2}$ metal complexes in the ground and sp excited states," Comments on Inorganic Chemistry, vol. 14, pp. 245-261, 1993.

[26] H. Nikol and A. Vogler, "Photoluminescence of antimony(III) and bismuth(III) chloride complexes in solution," Journal of American Chemical Society, vol. 113, pp. 8988-8990, 1991.

[27] H. Nikol, A. Becht, and A. Vogler, "Photoluminescence of germanium(II), tin(II), and lead(II) chloride complexes in solution," Inorganic Chemistry, vol. 31, no. 15, pp. 3277-3279, 1992.

[28] A. Vogler and H. Nikol, "Photochemistry and photophysics of coordination compounds of the main group metals," Pure and Applied Chemistry, vol. 64, no. 9, pp. 1311-1317, 1992. 

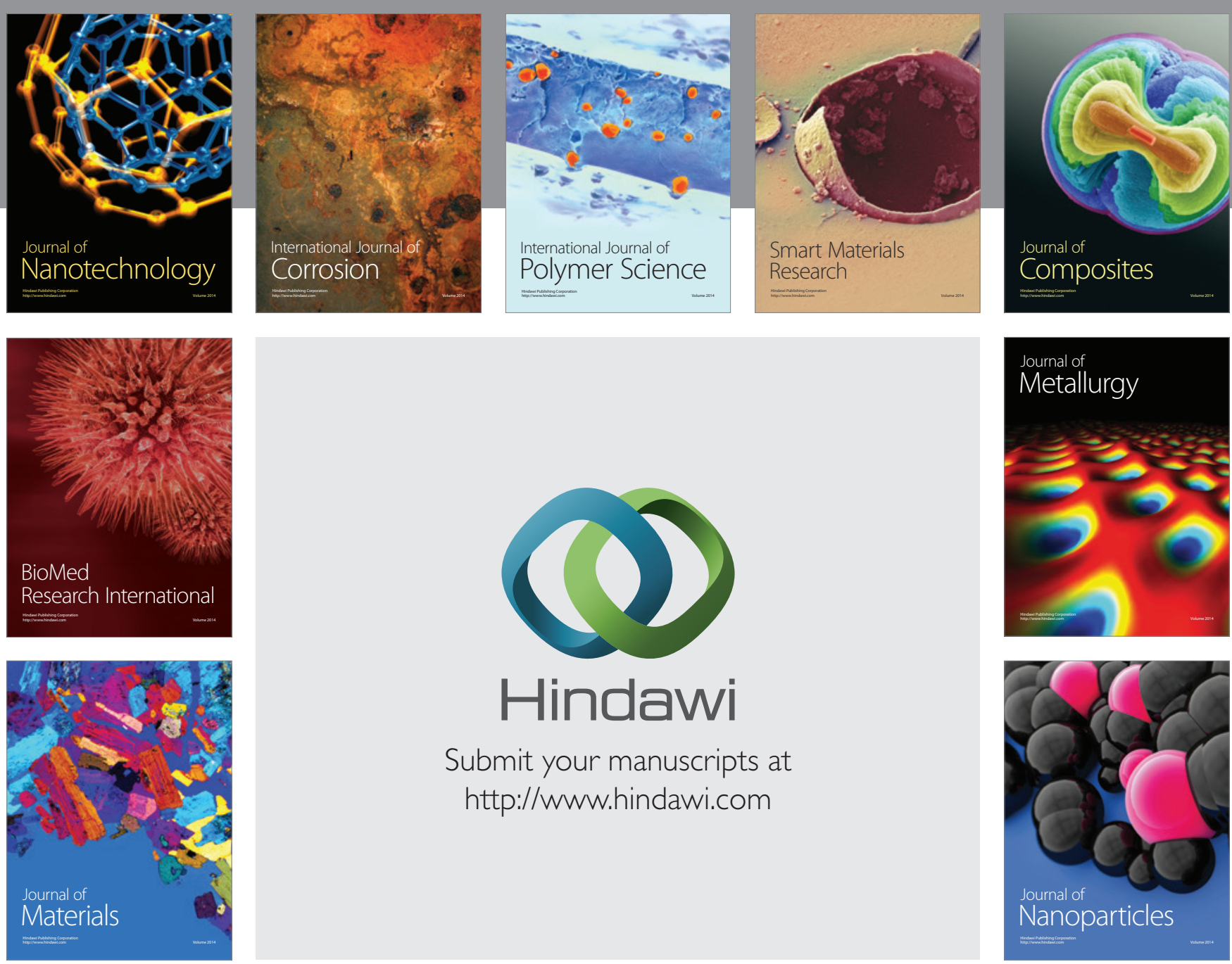

Submit your manuscripts at http://www.hindawi.com
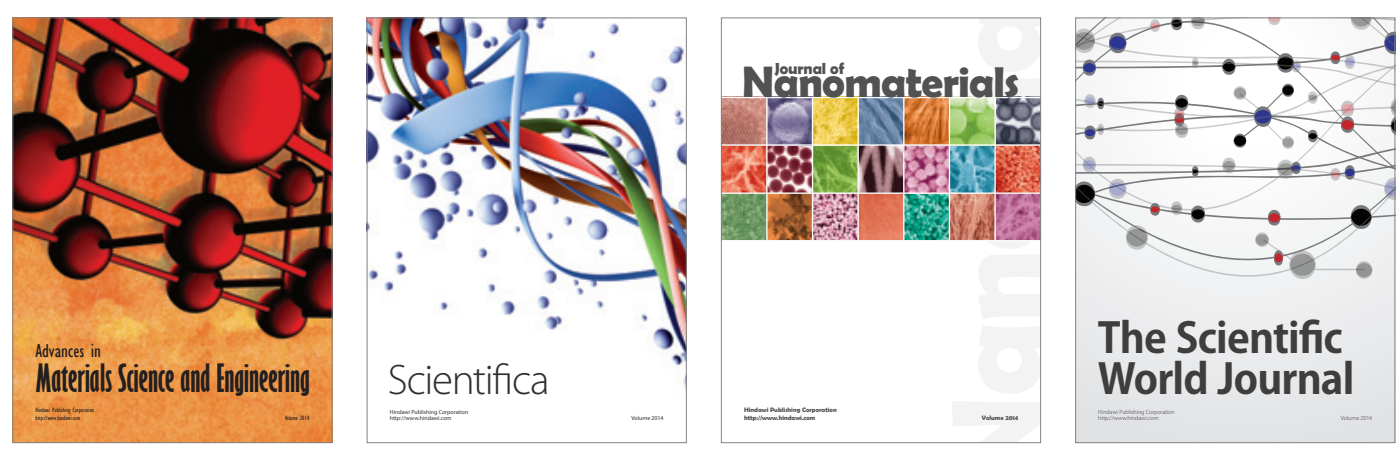

\section{The Scientific World Journal}
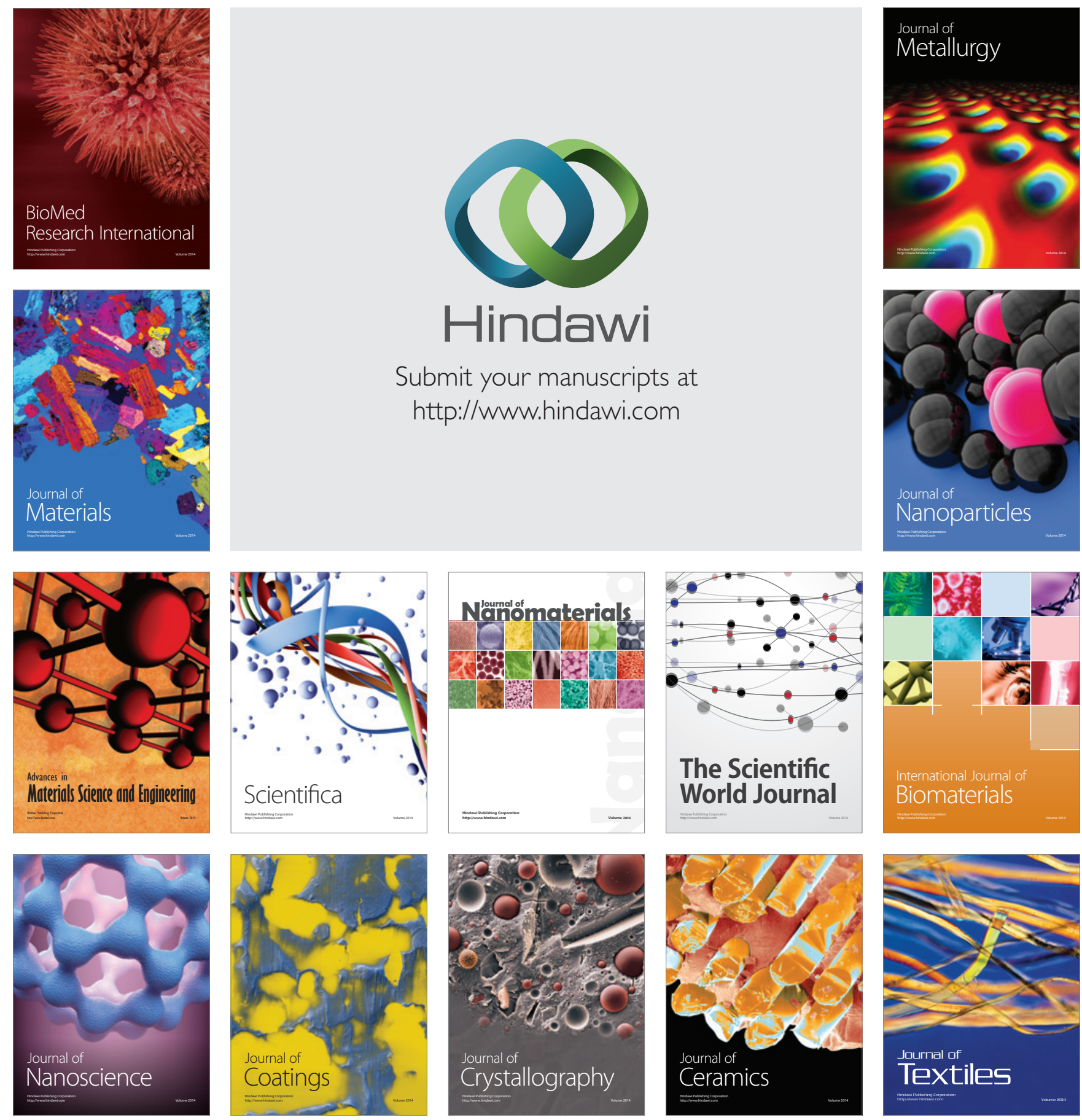